\title{
TU/e emonownen

\section{Atmospheric pressure plasma analysis by modulated molecular beam mass spectrometry}

\section{Citation for published version (APA):}

Aranda Gonzalvo, Y., Whitmore, T. D., Rees, J. A., Seymour, D. L., \& Stoffels - Adamowicz, E. (2006). Atmospheric pressure plasma analysis by modulated molecular beam mass spectrometry. Journal of Vacuum Science and Technology A: Vacuum, Surfaces, and Films, 24(3), 550-553. https://doi.org/10.1116/1.2194938

DOI:

10.1116/1.2194938

Document status and date:

Published: 01/01/2006

\section{Document Version:}

Publisher's PDF, also known as Version of Record (includes final page, issue and volume numbers)

\section{Please check the document version of this publication:}

- A submitted manuscript is the version of the article upon submission and before peer-review. There can be important differences between the submitted version and the official published version of record. People interested in the research are advised to contact the author for the final version of the publication, or visit the $\mathrm{DOI}$ to the publisher's website.

- The final author version and the galley proof are versions of the publication after peer review.

- The final published version features the final layout of the paper including the volume, issue and page numbers.

Link to publication

\section{General rights}

Copyright and moral rights for the publications made accessible in the public portal are retained by the authors and/or other copyright owners and it is a condition of accessing publications that users recognise and abide by the legal requirements associated with these rights.

- Users may download and print one copy of any publication from the public portal for the purpose of private study or research.

- You may not further distribute the material or use it for any profit-making activity or commercial gain

- You may freely distribute the URL identifying the publication in the public portal.

If the publication is distributed under the terms of Article 25fa of the Dutch Copyright Act, indicated by the "Taverne" license above, please follow below link for the End User Agreement:

www.tue.nl/taverne

Take down policy

If you believe that this document breaches copyright please contact us at:

openaccess@tue.nl

providing details and we will investigate your claim. 


\title{
Atmospheric pressure plasma analysis by modulated molecular beam mass spectrometry*
}

\author{
Y. Aranda Gonzalvo, ${ }^{\text {a) }}$ T. D. Whitmore, J. A. Rees, and D. L. Seymour \\ Hiden Analytical Ltd., 420 Europa Boulevard, Warrington WA5 7UN, England \\ E. Stoffels \\ Eindhoven University of Technology, P.O. Box 513, 5600 MB Eindhoven, The Netherlands
}

(Received 2 December 2005; accepted 20 March 2006; published 26 April 2006)

\begin{abstract}
Fractional number density measurements for a rf plasma "needle" operating at atmospheric pressure have been obtained using a molecular beam mass spectrometer (MBMS) system designed for diagnostics of atmospheric plasmas. The MBMS system comprises three differentially pumped stages and a mass/energy analyzer and includes an automated beam-to-background measurement facility in the form of a software-controlled chopper mechanism. The automation of the beam modulation allows the neutral components in the plasma to be rapidly and accurately measured using the mass spectrometer by threshold ionization techniques. Data are reported for plasma generated by a needle plasma source operated using a helium/air mixture. In particular, data for the conversion of atmospheric oxygen and nitrogen into nitric oxide are discussed with reference to its significance for medical applications such as disinfecting wounds and dental cavities and for microsurgery. (c) 2006 American Vacuum Society. [DOI: 10.1116/1.2194938]
\end{abstract}

\section{INTRODUCTION}

Electrical plasmas operating at atmospheric pressures are becoming increasingly popular for the surface treatment of a wide variety of materials that are not suitable for treatment under low, near vacuum, conditions. ${ }^{1-3}$ Highly functional surfaces can be produced on materials such as plastics and polymers, ${ }^{4}$ including woven and unwoven textiles. ${ }^{5}$ Other applications of atmospheric plasmas include the purification of water, ${ }^{6}$ the sterilization of surgical instruments, ${ }^{7,8}$ and localized treatment of biological samples. ${ }^{9}$ The plasmas of current interest range from those with large surface areas and substantial output powers, including surface barrier devices, to much lower power devices suitable for precision medical applications such as microsurgery. The simple plasma needle device developed at the University of Eindhoven ${ }^{9-12}$ is a good example of such a plasma source.

In all of the technological and medical applications of atmospheric plasmas an understanding of the gas phase and surface chemistry involved is important in order to develop and refine the particular application. As in the case of plasmas at low pressure, mass spectrometric diagnostics are proving to be of considerable value, especially when coupled with measurements of the energies of the active species controlling the plasma and interacting with the target surface. Since the central component of a mass spectrometer requires a low pressure regime, instruments for use with atmospheric plasmas require a pressure reduction interface. In the present work, the mass spectrometer employs a molecular beam inlet system which incorporates differentially pumped, pressure

\footnotetext{
*No proof corrections received from author prior to publication.

a) Electronic mail: gonzalvo@ hiden.co.uk
}

reduction stages. The instrument is also designed to have beam modulation provided by a mechanical chopper disk controlled by a software package.

Similar molecular beam inlet systems consisting of several differentially pumped stages coupled by sampling/ collimating apertures were used by Dayton and Frederick to determine reaction kinetics for high pressure combustion and pyrolysis processes. ${ }^{13}$ More recently they have been developed by Singh et al. ${ }^{14}$ for accurate measurement of radical densities in low pressure plasmas. In the present work, the plasma source was a small point/plane device based on the needle source described by Stoffels et al. ${ }^{9}$ The results obtained for an atmospheric plasma operated in a mixture of helium and room air suggest how the production of nitric oxide in such a device may be optimized for biological applications. They also demonstrate the capabilities of the molecular beam mass spectrometer (MBMS) instrument for diagnostics of such plasmas.

\section{DIAGNOSTIC APPARATUS}

\section{A. Molecular beam mass spectrometer}

The MBMS system incorporates a Hiden EQP mass/ energy analyzer. The EQP's inlet orifice is provided in the MBMS instrument by the final orifice of the differentially pumped, three-stage inlet system. A detailed view of the mass spectrometer inlet system is shown in Fig. 1. The sampling orifices are carefully aligned to produce a molecular beam which minimizes the collisions of the sampled particles with each other and with surfaces. The mechanical chopper mechanism (for simplicity not shown in Fig. 1) is mounted between the second and third pumping stages. It incorporates an optodetector positioned on the opposite side of its rotating disk to the molecular beam aperture. This generates a synchronization signal that is phase locked to the 


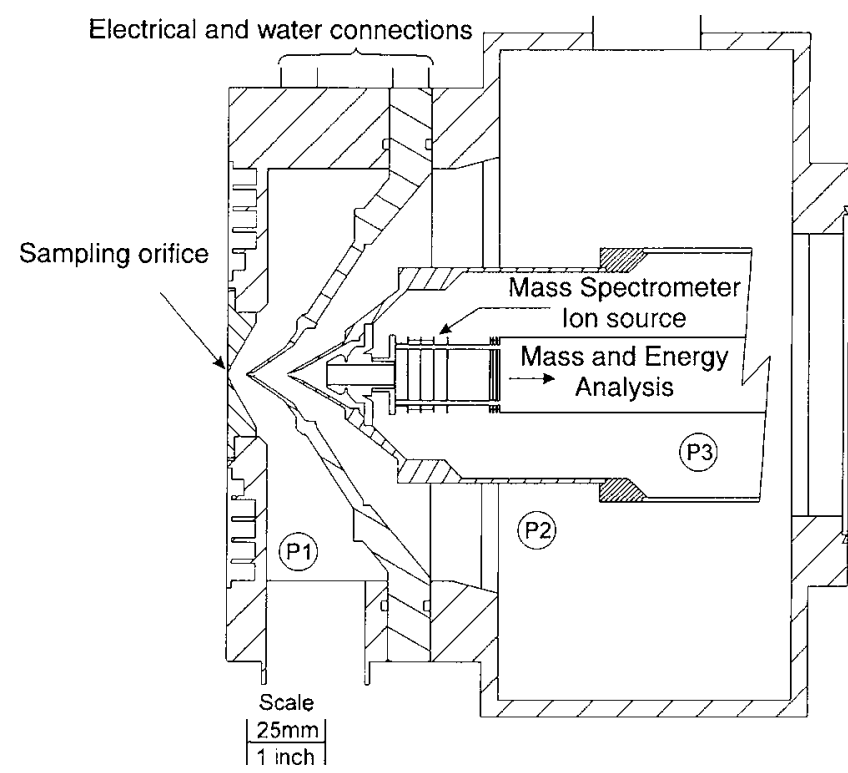

FIG. 1. Schematic of the MBMS Analyzer. P1, P2, and P3 represent the first, second, and third stage pressure reductions, respectively.

chopper movement and used by the mass spectrometer to provide two virtual detectors, identified as "foreground" and "background."

The mass spectrometer has one physical detector, namely, a secondary electron multiplier (SEM) detector, which may be connected to either the foreground or background virtual detectors under the control of the gating system. The detectors are presented as separate inputs by the control software and are related as follows:

$$
\begin{aligned}
& \text { SEM = foreground + background, } \\
& \text { foreground = SEM - background, } \\
& \text { background = background. }
\end{aligned}
$$

To compensate for the flight/transit time of the ions through the mass spectrometer, two internal pulse generators (100 ns resolution) are used to generate variable delays which allow matching of the beam chopping cycle to the foreground and background gatings, as shown in Fig. 2. In this way, synchronization between the gating signal from the beam chopper and the detector of the mass spectrometer gives an output information in the form

$$
\begin{aligned}
\text { background }= & \text { signal obtained when the molecular } \\
& \text { beam is blocked, }
\end{aligned}
$$

foreground = signal obtained from the molecular beam .

\section{B. Plasma source}

The plasma system used in the present work is based on a prototype plasma needle. ${ }^{9}$ Nonthermal atmospheric plasma is generated by applying a $13.56 \mathrm{MHz}$ rf power supply to a tungsten wire (50 $\mathrm{mm}$ long, $1 \mathrm{~mm}$ diameter). The discharge

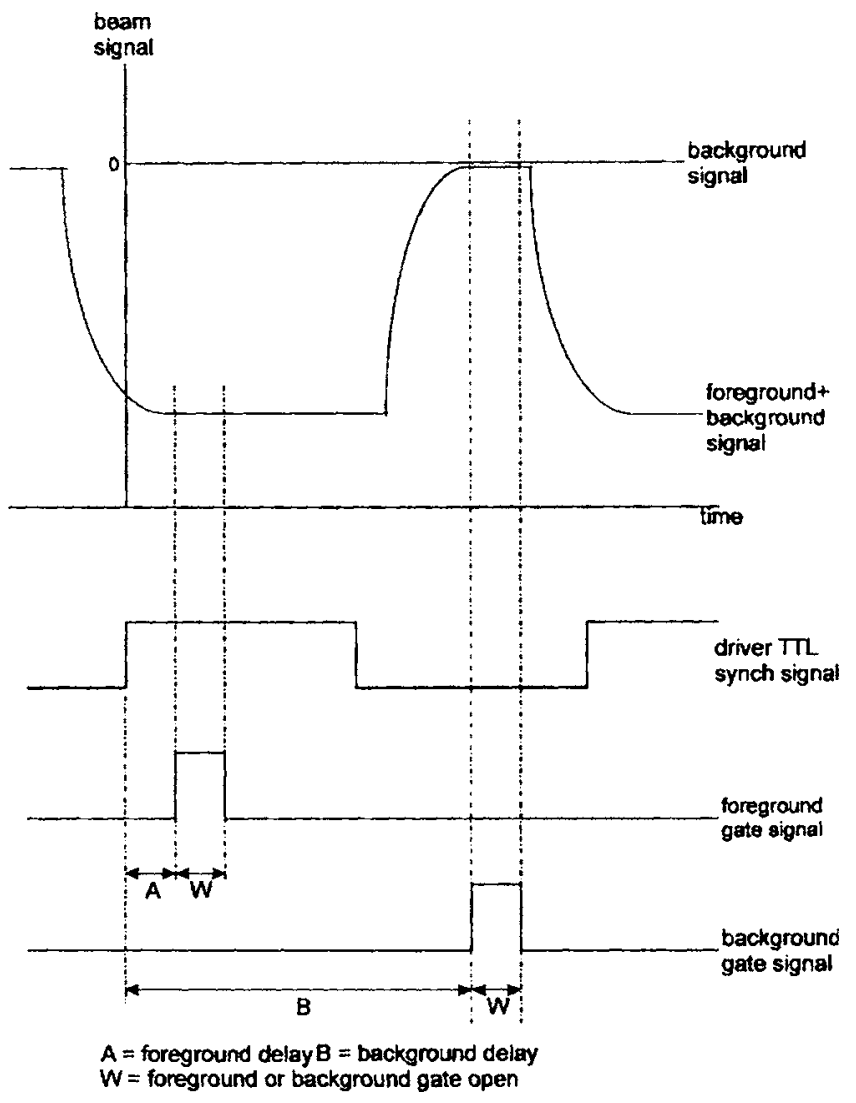

FIG. 2. Modulation timing diagram.

is produced between the end of the wire and the entrance of the MBMS analyzer. The power consumption is typically a few watts. The plasma is ignited in a mixture of helium and air.

\section{RESULTS}

\section{A. Threshold ionization: beam-to-background ratio}

The radicals and neutrals are ionized in the source of the EQP by electron impact. By varying the energy of the electrons used in the source it is possible to determine the appearance potentials of the ions generated from particular radical or neutral species. Plots of the ion signal as a function of the electron energy as this moves through the appearance potential are routinely used to study the ionization of the radicals and to determine their absolute number densities. $^{14-17}$

In the present work the threshold ionization (foreground detector) is scanned automatically, as described earlier. Figure 3 shows typical data in this case for the threshold ionization (appearance potential) of $\mathrm{N}^{+}$obtained from the helium discharge operating in ambient air. The two observed thresholds correspond to the direct and dissociative ionization processes;

$$
\begin{aligned}
& \mathrm{N}+e \rightarrow \mathrm{N}^{+}+2 e\left(E_{l}=16.5 \mathrm{eV}\right) \text { and } \\
& \mathrm{N}_{2}+e \rightarrow \mathrm{N}^{+}+\mathrm{N}+2 e\left(E_{l}=25.2 \mathrm{eV}\right)
\end{aligned}
$$




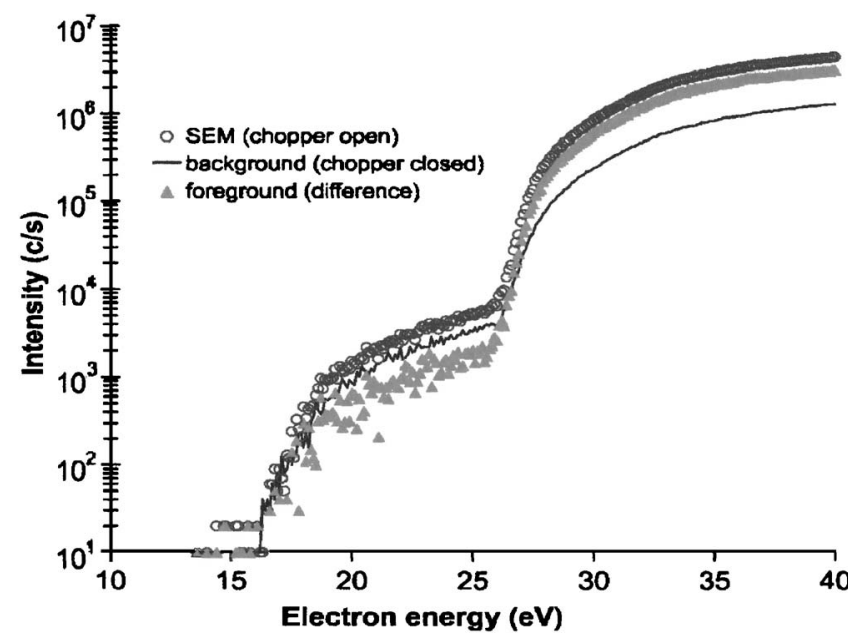

FIG. 3. Threshold ionization curves for $\mathrm{N}^{+}$. The threshold for the dissociative ionization of $\mathrm{N}_{2}$ is $25.2 \mathrm{eV}$.

The contribution of the background sources to the beam signal from the plasma can be calculated from the three curves of Fig. 3 and gives a figure of merit for the sensitivity of the overall apparatus. ${ }^{14,15}$ This in turn determines the accuracy of the calculations of the absolute, radical number densities. ${ }^{15}$ For the $\mathrm{N}^{+}$data shown in Fig. 3, the figure of merit can be shown to be 0.95 , i.e., the background addition to the beam signal from the plasma is only $5 \%$, and clearly demonstrates the sensitivity of the apparatus for absolute determinations of radical densities produced by atmospheric plasmas.

\section{B. Measurements using the plasma needle}

Molecular species have been sampled in order to determine the gas composition in the neutral gas surrounding the needle. The actual air and helium percentages in the gas mixture have been calculated by means of simple calibration of the mass spectrometer signals against the pure air signal. Stable plasmas could be obtained in air-helium atmospheres containing down to $20 \%$ helium. Data were collected for

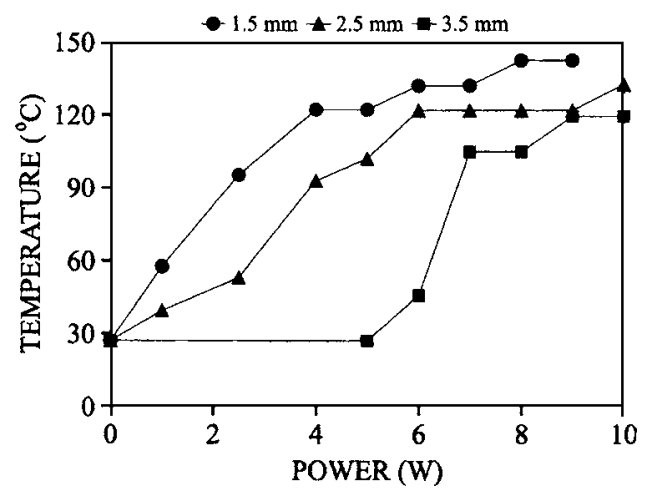

FIG. 4. Estimated gas temperature in the plasma at different power discharge values for different needles to MBMS orifice entrance distances.

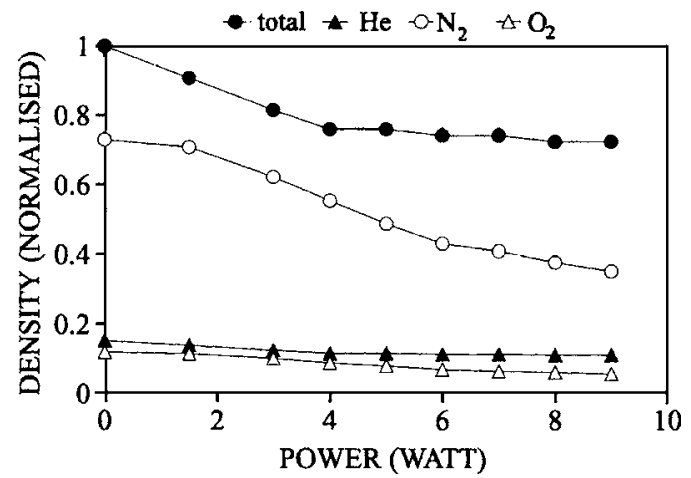

FIG. 5. Fractional number densities (in fractions of $1 \mathrm{~atm}=2.69 \times 10^{25} \mathrm{~m}^{-3}$ ) of various gases in the plasma at different power discharge values. The needle is at $1.5 \mathrm{~mm}$ distance to the MBMS orifice entrance.

different values of plasma parameters such as power and electrode gap (the distance between the probe tip and the MBMS orifice).

When the plasma is ignited, the recorded signals of helium, nitrogen, and oxygen decrease. Since helium cannot be consumed in the plasma, this decrease of signal must be related to a temperature increase. Assuming a constant pressure, gas temperature in the plasma can be estimated as a function of applied power and needle-to-surface distance. The results shown in Fig. 4 are in good agreement with the earlier data obtained by means of optical emission spectroscopy. $^{9}$

For a comparative study of the species present in the atmospheric plasma discharge, the mass spectrometer signals have been converted into fractional number densities. The normalized number density of value 1 corresponds to the ambient density at $1 \mathrm{~atm}$ and $25{ }^{\circ} \mathrm{C}\left(2.69 \times 10^{25} \mathrm{~m}^{-3}\right)$. It can be seen that the densities of nitrogen and oxygen decrease more rapidly with increasing plasma power than the total gas density (the latter is due to temperature effects), Fig. 5.

To quantify the number density of the species ("the product density") created in the plasma, the difference between the total density and the sum of helium, nitrogen, and oxygen fractional densities is calculated. As shown in Fig. 6 most of this product signal is provided by the signal of NO. This

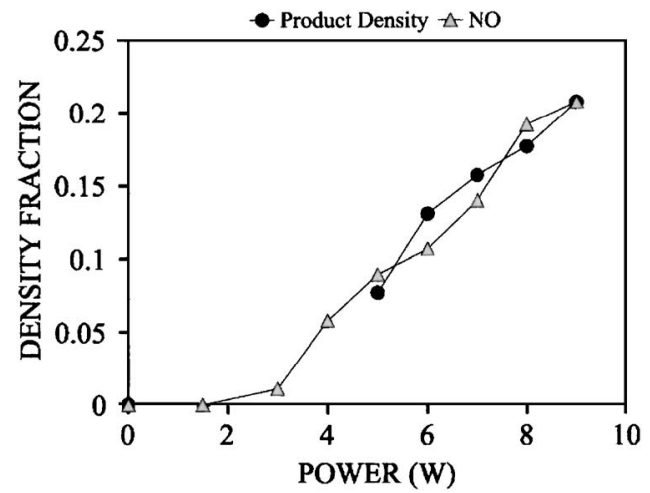

FIG. 6. "Product density" (difference between the total gas density and the sum of $\mathrm{He}, \mathrm{N}_{2}$, and $\mathrm{O}_{2}$ ) compared with a scaled $\mathrm{NO}$ signal as a function of the power discharge. The distance to the MBMS is $1.5 \mathrm{~mm}$. 


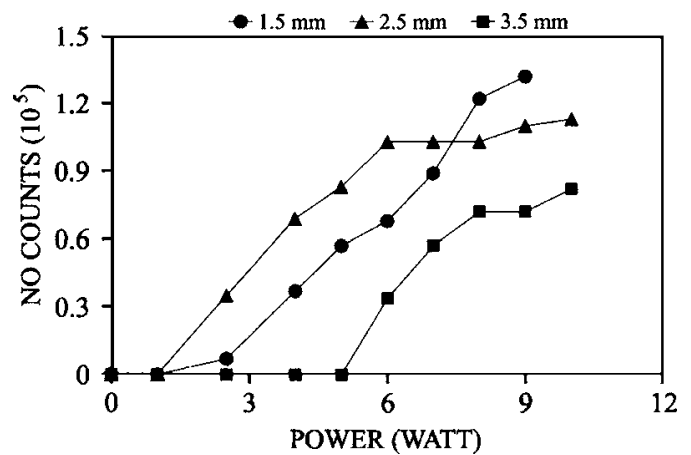

FIG. 7. Nitric oxide signals at various distances between the needle and the MBMS orifice entrance as a function of different discharge power values.

correlation holds at different needle-to-surface positions. Of course the product density can contain small contributions from other species, stable molecules, as well as radicals. Measurable signals of atomic nitrogen and oxygen as well as $\mathrm{OH}$ have been found, but they are much lower than the NO signal. Furthermore, we have searched for conversion products that could contribute to the product density, e.g., $\mathrm{NO}_{2}$ and $\mathrm{O}_{3}$. Their parent ions $\left(\mathrm{NO}_{2}{ }^{+}, \mathrm{O}_{3}{ }^{+}\right)$have not been found in the present spectra, but have been observed in other atmospheric plasmas (e.g. dielectric barrier discharges ${ }^{18}$ ). Thus, it can be assumed that for our conditions NO is the major product of conversion of feed gases. From the point of view of medical applications, this finding is very encouraging, because ozone and (especially) nitrogen dioxide are toxic and their presence in the plasma is not welcome. It is also promising that $\mathrm{NO}$ is the major conversion product, in view of the belief that it provides a major source of short wavelength UV radiation for sterilization of biological samples. ${ }^{19}$ It should be noted that the NO signal was not strongly dependent on the discharge gap, provided this was not too small (less than $2 \mathrm{~mm}$ ) (Fig. 7).

\section{CONCLUSIONS}

Molecular beam mass spectrometry has been successfully applied to atmospheric plasma sampling. Our scheme for automatic beam-to-background deconvolution allows for rapid and accurate determination of absolute radical number densities. The plasma needle exhibits a satisfactory stable operation for a small proportion of helium in the working gas mixture. This implies that in medical applications, reducing the supply of costly helium can make a major saving. Moreover, when the plasma is rich in air the composition seems to be optimized for the production of the therapeutically important radical $\mathrm{NO}^{20}$

${ }^{1} \mathrm{~J}$. R. Roth, Industrial Plasma Engineering: Applications to Nonthermal Plasma Processing (IOP, Bristol and Philadelpia, 2001).

${ }^{2}$ M. J. Shenton and G. C. Stevens, J. Phys. D 34, 2761 (2001).

${ }^{3}$ G. S. Selwyn, H. W. Herrmann, J. Park, and I. Henins, Contrib. Plasma Phys. 41, 610 (2001).

${ }^{4}$ M. Noeske, J. Degenhardt, S. Strudthoff, and U. Lommatzsch, Int. J. Adhes. Adhes. 24, 171 (2004).

${ }^{5}$ S. Pane, R. Tedesco, and R. Greger, J. Ind. Text. 31, 135 (2001)

${ }^{6}$ P. Sunka, Phys. Plasmas 8, 2587 (2001).

${ }^{7}$ J. R. Roth, D. M. Sherman, R. B. Gadri, F. Karakaya, Z. Chen, T. C. Montie, and K. Kelly-Winterberg, IEEE Trans. Plasma Sci. 28, 56 (2000).

${ }^{8}$ M. Laroussi, G. S. Sayler, B. B. Glascock, B. McCurdy, M. E. Pearce, N. G. Bright, and C. M. Malott, IEEE Trans. Plasma Sci. 27, 34 (1999).

${ }^{9}$ E. Stoffels, A. J. Flikweert, W. W. Stoffels, and G. M. W. Kroesen, Plasma Sources Sci. Technol. 11, 383 (2002).

${ }^{10}$ I. E. Kieft, J. L. V. Broers, V. Caubet-Hilloutou, F. C. S. Ramaekers, D. W. Slaaf, and E. Stoffels, Bioelectromagnetics (N.Y.) 25, 362 (2004).

${ }^{11}$ R. E. J. Sladek, E. Stoffels, R. Walraven, P. J. A. Tielbeek, and R. A. Koolhoven, IEEE Trans. Plasma Sci. 32, 1540 (2004).

${ }^{12}$ I. E. Kieft, J. J. B. N. Van Berkel, E. R. Kieft, and E. Stoffels, Plasma Proc. Polym. 1, 295 (2005).

${ }^{13}$ D. Dayton and W. Frederick, Energy Fuels 10, 284 (1996).

${ }^{14}$ H. Singh, J. W. Coburn, and D. B. Graves, J. Vac. Sci. Technol. A 17, 2447 (1999).

${ }^{15}$ S. Agarwal, G. W. W. Quax, M. C. M. Van de Sanden, D. Maroudas, and E. S. Aydil, J. Vac. Sci. Technol. A 22, 71 (2004).

${ }^{16}$ C. A. Rego, R. S. Tsang, P. W. May, M. N. R. Asfold, and K. N. Rosser, J. Appl. Phys. 79, 7264 (1996).

${ }^{17}$ P. Kae-Nune, J. Perrin, J. Guillon, and J. Jolly, Jpn. J. Appl. Phys., Part 1 33, 4303 (1994).

${ }^{18}$ M. Laroussi, Second International Workshop on Cold Atmospheric Pressure Plasmas: Sources and Applications, Bruges, Belgium, 2005 (unpublished), p. 18.

${ }^{19}$ M. Moisan, B. Saoudi, M. C. Crevier, N. Philip, E. Farard, J. Barbeau, and J. Pelletier, Fifth International Workshop on Microwaves Discharges, Greifswald, Germany, 2003 (unpublished), p. 18.

${ }^{20}$ R. E. Klabunde, Cardiovascular Physiology Concepts (Lippincott, New York, 2004), http://www.oucom.ohiou.edu/cvphysiology/BF011.htm. 